\title{
Functional specialization of retinal Müller cell endfeet depends on an interplay between two syntrophin isoforms
}

\author{
Shirin Katoozi ${ }^{1 \dagger}$, Shreyas B. Rao ${ }^{1 \dagger}$, Nadia Skauli ${ }^{1}$, Stanley C. Froehner ${ }^{2}$, Ole Petter Ottersen ${ }^{1,3}$, Marvin E. Adams ${ }^{2}$ and \\ Mahmood Amiry-Moghaddam ${ }^{1 *}$
}

\begin{abstract}
Retinal Müller cells are highly polarized macroglial cells with accumulation of the aquaporin-4 (AQP4) water channel and the inwardly rectifying potassium channel $\mathrm{K}_{\mathrm{ir}} 4.1$ at specialized endfoot membrane domains abutting microvessels and corpus vitreum. Proper water and potassium homeostasis in retina depends on these membrane specializations. Here we show that targeted deletion of $\beta 1$-syntrophin leads to a partial loss of AQP4 from perivascular Müller cell endfeet and that a concomitant deletion of both a1-and $\beta 1$-syntrophin causes a near complete loss of AQP4 from both perivascular and subvitreal endfoot membranes. a1-syntrophin is normally very weakly expressed in Müller cell endfeet but $\beta 1$-syntrophin knockout mice display an increased amount of a1syntrophin at these sites. We suggest that upregulation of perivascular a1-syntrophin restricts the effect of $\beta 1$ syntrophin deletion. The present findings indicate that $\beta 1$-syntrophin plays an important role in maintaining the functional polarity of Müller cells and that a1-syntrophin can partially substitute for $\beta 1$-syntrophin in AQP4 anchoring. Functional polarization of Müller cells thus depends on an interplay between two syntrophin isoforms.
\end{abstract}

Keywords: AQP4, $\beta 1$-syntrophin, a1-syntrophin, Polarization, Retina, Müller cell

\section{Introduction}

Macroglia are polarized cells whose functions are governed by distinct membrane domains that are specialized in terms of their structure, function and molecular composition [1-4]. Müller cells - a specialized class of retinal macroglia - have figured prominently in research on glial function and glial polarization [3]. Early studies on Müller cells revealed a strikingly uneven distribution of $\mathrm{K}^{+}$conductance along the plasma membrane, with particularly high conductance in membrane domains facing vessels and corpus vitreum [5-12]. This finding laid the

\footnotetext{
* Correspondence: mahmo@medisin.uio.no.

Shirin Katoozi and Shreyas B. Rao are Shared first author.

'Division of Anatomy, Department of Molecular Medicine, Institute of Basic Medical Sciences, University of Oslo, Post box 1105, Blindern, 0317 Oslo, Norway

Full list of author information is available at the end of the article
}

foundation for our current understanding of how macroglia removes excess $\mathrm{K}^{+}$by siphoning and spatial buffering [13-15]. Later studies identified the biochemical substrate for this functional specialization. Thus it was found that Müller cell processes that abut on retinal vessels or corpus vitreum contain high concentrations of the inwardly rectifying $\mathrm{K}^{+}$channel $\mathrm{K}_{\mathrm{ir}} 4.1$ [16-18]. Immunogold analyses showed that the very same endfoot domains also contain high densities of the water channel aquaporin-4 (AQP4) [16]. Taken together, functional and immunogold studies indicate that Müller cells - and macroglia in general - are endowed with specific membrane domains that are uniquely involved in $\mathrm{K}^{+}$and water homeostasis $[1,4,19,20]$.

Immunoelectron microscopy revealed a loss of AQP4 from glial endfoot membranes in hippocampal specimens obtained from patients with mesial temporal lobe 
epilepsy [21]. More recent experimental observations indicate that loss of macroglial polarization occurs not only in epilepsy but also in stroke, edema and Alzheimer's disease [22-26]. Indeed, loss of macroglial polarization may be a key pathophysiological event common to a wide range of neurological conditions. This begs the question of how macroglial polarization is established and maintained.

The first evidence that syntrophins are essential for glial polarization came with the study of Neely et al. [27], which indicated that AQP4 is linked to a dystrophin associated protein complex (DAP complex) through $\alpha 1$-syntrophin ( $\alpha 1$ syn). In agreement, mice lacking $\alpha 1$-syn showed a loss of AQP4 from astrocyte endfeet in hippocampus and delayed clearance of $\mathrm{K}^{+}$following high frequency synaptic activation [28]. A more recent study corroborates the idea that $\alpha 1$-syn is the single most important factor determining the size of the AQP4 pool in brain astrocytic endfeet [29]. However, deletion of $\alpha 1$-syn did not cause any significant loss of AQP4 from endfeet of retinal Müller cells [30], pointing to the existence of alternative anchoring mechanisms.

Here we exploit a newly generated transgenic mouse line [31] to investigate whether functional polarization of Müller cells depends on $\beta 1$-syntrophin ( $\beta 1$-syn). We have previously used this mouse line to assess the role of $\beta 1$-syn in anchoring of $K_{i r} 4.1$ [32]. The present study shows that $\beta 1$-syn is the most important anchor of AQP4 in Müller cell processes but that $\alpha 1$-syn may partly substitute as anchor if $\beta 1$-syn is lost. The unraveling of the mechanisms underlying Müller cell polarization opens new avenues for the understanding of glial function in normal brain and in disease.

\section{Materials and methods Animals}

Age matched adult male (3- to 6- month old) mice with targeted deletion of the genes encoding $\alpha 1$-syn or $\beta 1$-syn ( $\alpha 1$-syn $\mathrm{KO}$ and $\beta 1$-syn $\mathrm{KO}$, respectively), or both genes ( $\alpha \beta 1$-syn KO, generated by crossing $\alpha 1$-syn $\mathrm{KO}$ and $\beta 1$ syn KO mice) were used in this study. Mice of C57/BL6 background were used as wild type controls (WT). The details regarding generation and characterization of these mice are described previously $[31,33]$. In addition, mice lacking the gene for AQP4 (AQP4 KO) were used as controls for antibody specificity [34]. Animals had access to food and water ad libitum. All the experimental procedures performed on mice were approved by the Institutional Animal Care and Use Committee of the University of Washington (\#3298-02) and according to the European Council law on protection of laboratory animals, with the approval of the University of Oslo's Animal Care and Use Committee (FOTS ID 8572). Every effort was made to minimize the number of animals.

\section{Perfusion and tissue preparation}

Mice were anesthetized using isoflurane and then transcardially perfused with initial $20-30 \mathrm{~s}$ of ice cold $2 \%$ dextran in $0.1 \mathrm{M}$ phosphate buffer $(\mathrm{PB})$. The animals were perfusion fixed by using $\mathrm{pH}$-shift protocol [35] where fixation was carried out using $4 \%$ formaldehyde and $0.2 \%$ picric acid in $0.1 \mathrm{M} \mathrm{PB}$ at $\mathrm{pH} 6.0$ for $5 \mathrm{~min}$, followed by the same fixative at $\mathrm{pH} 10.0$ for $15 \mathrm{~min}$. The eyes were dissected out, post fixed overnight and later stored in 1:10 dilution of the fixative in PB until further processing.

\section{Post embedding}

Post embedding procedure was performed as previously described [36]. Briefly, small blocks of retina were dissected, cryoprotected in graded glycerol solution $(10,20$ and $30 \%$ of glycerol in $0.1 \mathrm{M} \mathrm{PB}$ ) and quickly frozen in propane cooled to $-170{ }^{\circ} \mathrm{C}$ in liquid nitrogen and subjected to freeze substitution. The samples were then embedded in methacrylate resin (Lowicryl HM20) and polymerized by UV light below $0{ }^{\circ} \mathrm{C}$. Ultrathin sections of 80-100 nm were cut using Ultratome (Reichert Ultracut S, Leica) and placed on formvar carbon coated support film in Ni-grids.

\section{Immunogold electron microscopy}

Immunogold labeling was performed as previously described [37]. Briefly, sections were rinsed in Tris-Buffered saline with Triton X-100 (TBST; $0.05 \%$ Tris- $\mathrm{HCl}, 0.9 \%$ $\mathrm{NaCl}$ and $0.1 \%$ Triton $\mathrm{X}-100$ ), followed by the incubation with $2 \%(\mathrm{w} / \mathrm{v})$ human serum albumin (HSA) at room temperature (RT) for $10 \mathrm{~min}$. The sections were incubated with primary antibody overnight, followed by incubation with secondary goat anti-rabbit IgG antibody conjugated to $15 \mathrm{~nm}$ colloidal gold particle (1:20 dilution; Abcam; Cat\#: ab27236; RRID:AB_954457) for $2 \mathrm{~h}$. The sections were contrasted with $2 \%$ uranyl acetate and $0.3 \%$ lead citrate for $90 \mathrm{~s}$ each and examined using Tecnai 12 transmission electron microscope (FEI, Hillsboro, OR) at $80 \mathrm{kV}$.

Primary antibodies were: i) affinity-purified rabbit polyclonal antibody against AQP4 (1:400 dilution; Sigma Aldrich; Cat\# A5971; RRID:AB_258270); ii) affinity-purified rabbit polyclonal antibody against $\alpha 1$-syn (SYN259; 1:100 dilution) which has previously been validated [38].

\section{Immunogold quantitation}

Images (totaling 1200) from outer plexiform layer (OPL), inner plexiform layer (IPL), ganglion cell layer (GCL), and subvitreous domain (Sub) of the retinae were acquired from each section and genotype. Care was taken to distinguish the different layers of the retina while taking the images at a magnification of 26,500x. Previous studies have shown an asymmetric distribution of AQP4 around the blood vessels of GCL [39]. In order to ensure proper sampling, images of vessels in the GCL 
were taken from the outer aspect of the retina where AQP4 was shown to be expressed. Quantification was performed as mean linear densities of gold particles by counting the gold particles within $23.5 \mathrm{~nm}$ of the inner leaflet of the membranes of interest $[40,41]$ using analySIS program (Soft Imaging Systems (SIS), Münster, Germany). In a separate experiment, AQP4 KO mice $(n=2)$ were used as controls for antibody specificity and the images of the vessels were acquired from OPL, IPL and GCL of retina.

\section{Immunofluorescence}

For light microscopic immunofluorescence experiments, the perfusion fixed eyes were cryoprotected in gradient sucrose solution $(10,20$ and $30 \%$ of sucrose in $0.1 \mathrm{M} \mathrm{PB}$ ) before being frozen in OCT medium (Richard-Allan Scientific ${ }^{\text {mi }}$ Neg$50^{\mathrm{ma}}$, Thermo Fisher Scientific; Cat\#: 6502) using dry ice. Sections were cut at a thickness of $14 \mu \mathrm{m}$ and were adhered on to glass slides and stored at $-80^{\circ} \mathrm{C}$ until further use.

For immunofluorescence, the sections were thawed at RT, rinsed with phosphate buffer saline (PBS; $0.01 \mathrm{M}$ ) and were blocked using blocking solution (10\% normal donkey serum, $1 \%$ bovine serum albumin (BSA; w/v), $0.5 \%$ triton in PBS) for $60 \mathrm{~min}$. The sections were incubated overnight with affinity-purified rabbit polyclonal antibody against AQP4 (1:400 dilution; Sigma Aldrich; Cat\# A5971; RRID:AB_258270) and mouse monoclonal antibody against Glutamine Synthetase (GS; 1:100 dilution; BD Biosciences; Cat\# 610518, RRID:AB_397880) that was diluted in blocking solution with addition of sodium azide $(0.01 \%)$. Following day, the sections were rinsed with PBS and then incubated with secondary antibodies diluted in blocking solution (Cy3 donkey-antirabbit; 1:500 dilution; Jackson ImmunoResearch Labs; Cat\#: 711-165-152; RRID:AB_2307443 and Cy2 donkeyanti-mouse; 1:500 dilution; Jackson ImmunoResearch Labs; Cat\#: 715-225-151; RRID:AB_2340827) for 1-2 h. Vessels were stained using DyLight 649 conjugated tomato lectin (LEL, TL; Vector labs; Cat\#: DL-1178). Nuclear staining was performed by incubating the sections with Hoechst 33258, (1:5000 dilution; Thermo Fisher Scientific; Cat\#: H3569; RRID:AB_2651133) for $5 \mathrm{~min}$ and mounted using ProLong ${ }^{\text {mi }}$ Gold Antifade Mountant (Thermo Fisher Scientific; Cat\#: P36934; RRID:SCR 015961). Images were acquired using LSM 710 confocal microscope at $40 \mathrm{x}$ or $63 \mathrm{x}$ magnification, water objective (Carl Zeiss). For immunofluorescence experiments with $\alpha 1-$ syn and $\beta 1$-syn antibodies, eyeballs were removed from decapitated animals and quickly frozen in OCT media in a cryomold cassette in liquid nitrogen. Cryosections were cut at $14 \mu \mathrm{m}$ thickness, adhered on to glass slides and stored at $-80^{\circ} \mathrm{C}$. Prior to staining, the sections were thawed to RT, fixed using $0.5 \%$ formaldehyde for $20 \mathrm{~min}$ and the staining procedure was continued as detailed above. The antibodies were diluted as follows: $\alpha 1$-syn (SYN259; 1:100 dilution) and $\beta 1$-syn (Syn248; 1:100 dilution). These antibodies have previously been validated [38].

\section{Real time PCR}

Detailed procedure for quantitative real-time PCR (qPCR) was performed as described in [32]. The primers used to detect Aqp4 were; Forward (5'): TTTGGACCCGCAGT TATCAT; Reverse (3'): GTTGTCCTCCACCTCCATGT. TATA-box binding protein $(T b p)$ was used as the normalization gene. The primers used to detect $T b p$ were; Forward (5'): ACGGACAACTGCGTTGATTT; Reverse (3'): CAAGGCCTTCCAGCCTTATAG.

\section{Preparation of total protein lysates, SDS-PAGE and western blot}

The detailed procedure for western blot analysis can be found as described in [32]. Briefly, $20 \mu \mathrm{g}$ protein from WT, $\alpha 1$-syn $\mathrm{KO}$ and $\beta 1$-syn $\mathrm{KO}$ male mouse retinae ( $n=5$ for each genotype) was separated on $10 \%$ Criterion $^{\text {tim }}$ 18-well TGX gels (BioRad, Hercules, CA, USA) at $160 \mathrm{~V}$ and wet blotted to PVDF membranes (BioRad) at $100 \mathrm{~V}$ for $45 \mathrm{~min}$. Membranes were blocked in 5\% BSA in $1 \mathrm{X}$ Tris-Buffered saline (TBS) for $1 \mathrm{~h}$ before overnight incubation with rabbit anti-aquaporin 4 (1:1000; SigmaAldrich; Cat\# A5971; RRID:AB_258270), rabbit anti- 1 1syn (1:1000; Abcam; Cat\# ab11187; RRID:AB_2191794) or rabbit anti- $\beta 1$-syn antibodies (Syn248; 1:1000 dilution) (Peters et al., 1997). Incubations with anti-HRP secondary antibodies (1:20000, Amersham, GE Healthcare; Cat\# NA934, RRID:AB_772206) were performed for $1 \mathrm{~h}$ before TBST washes and detection of immunoreactive bands by SuperSignal ${ }^{\text {Tw }}$ West Pico Chemiluminescent Substrate (Thermo Fisher) on a BioRad Touch system. Subsequently, mouse anti-GAPDH (1:1000; Abcam; Cat\# ab9484; RRID:AB_307274) was used as described for development of loading control bands.

\section{Statistical analysis}

All the statistical analyses were carried out in SPSS (SPSS, Chicago, IL, USA). Sample sizes were determined based on previous studies $[29,32]$. However, same number of animals were used for all the experiments. No data points or animals were excluded from any of the analyses.

For all western blot analyses ( $n=5$ for each genotype), bands were quantified as arbitrary background-subtracted density units in Image Studio Lite (Ver 5.2, Licor Biosciences, Nebraska, USA) and compared in SPSS Version 25 using independent samples t-test. Values are presented as percentage of the average wild-type values with mean values \pm SD. ${ }^{*} p<0.05$ was considered as significant.

For immunogold analyses, images were taken from four WT, four $\alpha 1$-syn $\mathrm{KO}$, four $\beta 1$-syn $\mathrm{KO}$ and four $\alpha \beta 1$-syn $\mathrm{KO}$ mice. The data obtained from analySIS was 
transferred to SPSS Version 23 (SPSS, Chicago, IL) for statistical analysis. The researcher was blinded to the genotype of the animals during the entire procedure. Comparisons between groups were made by one-way ANOVA and post hoc Scheffé tests. Data are presented as mean \pm SEM. ${ }^{*} p<.05 ; * *<<.01 ;{ }^{* * * *} p<.001$ were considered significant. Individual data points from each experiment is provided in 'Additional file 2'.

\section{Results}

Targeted deletion of the gene encoding $\beta 1$-syn does not affect transcript or protein level of AQP4

Western blot analysis on retinal protein lysates of $\beta 1$-syn $\mathrm{KO}$ mice did not show any noticeable bands corresponding to the molecular weight of $\beta 1$-syn (Fig. 1a). Successful knockout was also confirmed by qPCR and immunofluorescence [32]. The transcript level of Aqp4 was not changed after $\beta 1$-syn $\mathrm{KO}$ (Fig. 1b) and was also resistant to deletion of $\alpha 1$-syn, individually or in combination with deletion of $\beta 1$-syn (Additional file 1: Fig. S1). Western blot analysis of retinae with antibodies to AQP4 did not reveal any difference between $\beta 1$-syn KO mice and WT (Fig. 1c).

\section{Partial loss of perivascular AQP4 in mice with targeted deletion of $\beta 1$-syn is accentuated by concomitant knockout of a1-syn}

The perivascular endfoot membrane plays a critical role in the exchange of water between blood and brain $[28,42]$. Thus, we chose to focus on this membrane domain for further analysis with respect to AQP4 localization in retina. Our immunofluorescence analysis showed that targeted deletion of $\beta 1$-syn produced an increased AQP4 labeling in retinal neuropil (Fig. 2b,e). This increase was even more pronounced in mice with concomitant knockout of $\alpha 1$ - and $\beta 1$-syntrophin ( $\alpha \beta 1$-syn KO) (Fig. 2c, f). In contrast, perivascular AQP4 staining was markedly reduced in the $\alpha \beta 1$-syn KO mice (Fig. 2f). Whether perivascular labeling was attenuated also in $\beta 1$-syn $\mathrm{KO}$ mice could not be resolved by immunofluorescence analysis (Fig. 2b, e). An immunogold analysis was required.

In WT animals, immunogold particles signaling AQP4 were concentrated in perivascular endfoot membranes (Fig. 3a, d, g), consistent with the distinct and anatomically restricted immunofluorescence signal at this site. The linear density of AQP4 immunogold particles was highest in perivascular membranes of OPL and IPL and lowest in subvitreal endfoot membranes (Fig. 4a). Compared with WT, there was a noticeable reduction of AQP4 immunosignal in the perivascular endfoot membrane of $\beta 1$-syn $\mathrm{KO}$ mice (Fig. 3b, e, h). In agreement with the immunofluorescence data, immunogold analysis showed a dramatic loss of AQP4 immunogold particles from perivascular Müller cell membranes of the $\alpha \beta 1$-syn
KO mice (Fig. 3c, f, i). Antibody specificity was confirmed by analysis of sections from AQP4 KO retina (Additional file 1: Fig. S2 and Fig. S3).

Quantitative analysis of the immunogold experiments showed that the loss of perivascular AQP4 depended on the retinal layer and ranged between $\sim 32$ and $\sim 57 \%$ in $\beta 1$-syn $\mathrm{KO}$ and between $\sim 79$ and $\sim 94 \%$ in $\alpha \beta 1$-syn $\mathrm{KO}$ mice compared to WT (Fig. 4b).

Since combined deletion of $\alpha 1$ - and $\beta 1$-syn results in near depletion of perivascular AQP4, we set out to quantify the specific contribution by $\alpha 1$-syn. Consistent with previous data [30], mice with targeted deletion of $\alpha 1$-syn did not differ significantly from WT animals in regard to the density of AQP4 in Müller cell endfeet (Additional file 1: Fig. S4a-d, g-i). The total level of AQP4 protein was unchanged after $\alpha 1$-syn $\mathrm{KO}$ (Additional file 1: Fig. S4e,f).

Deletion of $\beta 1$-syn or $\alpha 1$-syn individually had no effect on AQP4 labeling in the subvitreal endfoot membrane (Fig. 5b, c, f, g, i). However, immunofluorescence and immunogold signals for AQP4 were dramatically decreased in retinae of $\alpha \beta 1$-syn $\mathrm{KO}$ mice (Fig. $5 \mathrm{~d}$, h, i; Additional file 1: Fig. S5).

Loss of $\beta 1$-syn results in increased expression of a1-syn Since $\alpha \beta 1$-syn KO led to a more dramatic loss of AQP4 than $\beta 1$-syn $\mathrm{KO}$, and since deletion of $\alpha 1$-syn alone did not result in any significant loss of perivascular AQP4, we asked whether deletion of $\beta 1$-syn would lead to compensatory changes of $\alpha 1$-syn. The hypothesis would be that in the absence of $\beta 1$-syn, $\alpha 1$-syn undergoes compensatory upregulation that helps tether a residual AQP4 pool to perivascular membranes. To test this, we performed western blot and quantitative immunogold analysis on WT and $\beta 1$-syn $\mathrm{KO}$ retinae.

Immunoblots revealed that $\beta 1$-syn $\mathrm{KO}$ led to an increased expression of $\alpha 1$-syn (Fig. 6a, b). In agreement, perivascular and subvitreal immunogold labelling for $\alpha 1$ syn is significantly increased in $\beta 1$-syn KO (Fig. 6c, d; Additional file 1: Fig. S6). Corroborating data were obtained by immunofluorescence analysis (Additional file 1: Fig. S7). In a previous study we found no change in $\alpha 1$-syn expression at mRNA level following targeted deletion of $\beta 1$-syn [32]. Furthermore, western blot and immunofluorescence analyses from retinae of WT and $\alpha 1$ syn $\mathrm{KO}$ mice showed no difference in the level of $\beta 1$-syn between the two genotypes (Fig. 7a-f). Thus, it appears that the upregulation of $\alpha 1$-syn in $\beta 1$-syn $\mathrm{KO}$ mice occurs at the translational or post-translational level.

\section{Discussion}

Müller cells are the archetypical class of macroglia for studies of homeostatic processes in the central nervous system. The realization that the anatomical polarization 


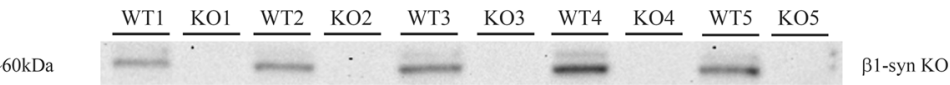

$\mathrm{b}$
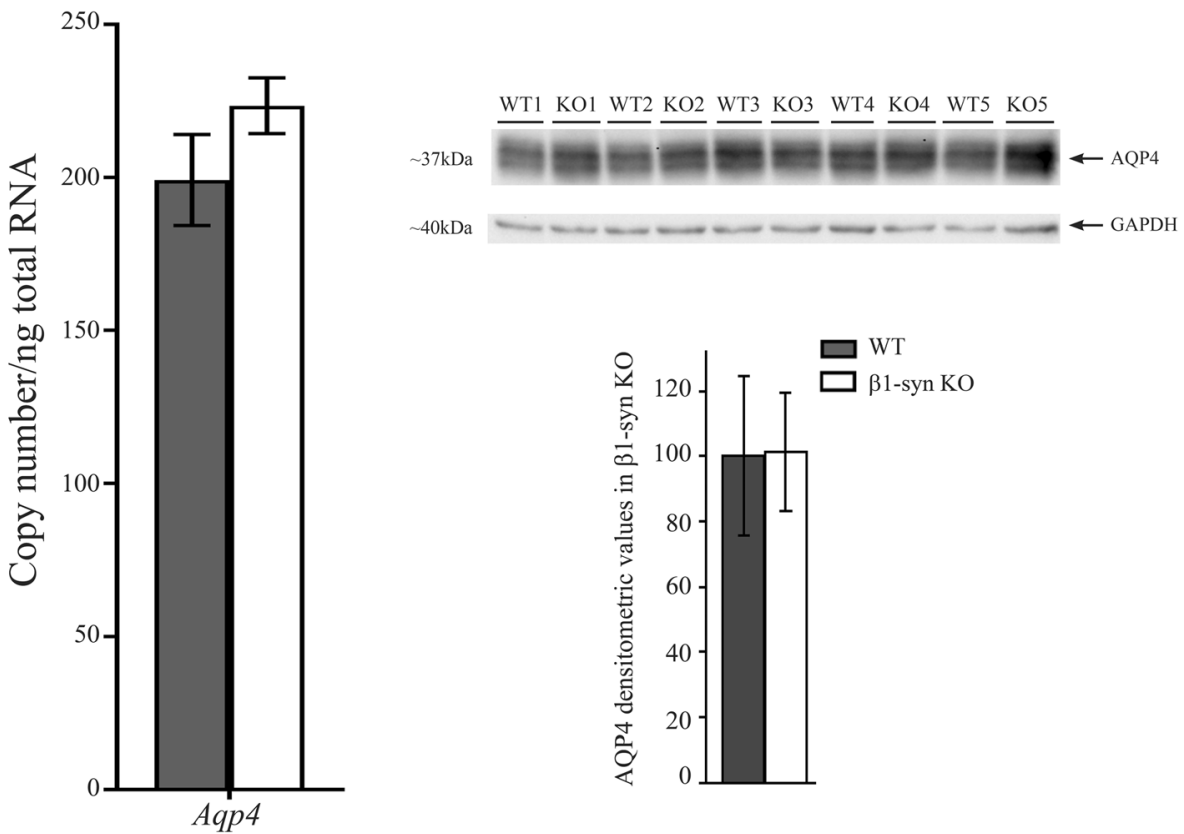

Fig. 1 Aqp4 expression in retinae of $\beta 1$-syn $\mathrm{KO}$ mice. a Immunoblot from total protein lysates of $\mathrm{WT}$ and $\beta 1$-syn $\mathrm{KO}$ retina samples. $\beta 1$-syn $\mathrm{KO}$ mice lack an immunoreactive protein band at $\sim 59 \mathrm{kDa}$ corresponding to $\beta 1$-syn, confirming the genotype. $\mathbf{b}$ qPCR analysis of total RNA extracted from eye using primers specific for Aqp4. No statistically significant difference in total Aqp4 gene expression was observed between the two genotypes ( $n=6$ for WT and $n=7$ for $\beta 1$-syn KO). Statistics: Mann-Whitney U-test. Tbp was used as the normalization gene. Data shown as mean \pm SEM. c Immunoblot showing AQP4 expression in total protein lysates from WT and $\beta 1$-syn KO retinae. Statistical analysis of AQP4 expression in WT and $\beta 1$-syn KO showed no difference in AQP4 protein expression between the two genotypes $(n=5$ for each group). Densitometric values are expressed as percentage of average WT values \pm SD. Statistics: independent samples t-test. GAPDH was used as the loading control

of macroglia has a functional and biochemical correlate stems in large measure from seminal studies of retinal Müller cells [5-9, 16, 22, 25, 39, 43, 44].

What are the mechanisms underlying the functional polarization that is so essential for glial physiology and pathophysiology? Obviously, the spatially restricted enrichment of specific membrane molecules must rely on distinct anchoring processes. The $\mathrm{C}$-terminus of AQP4 provided a clue as to the nature of these processes. Thus, AQP4 contains the C-terminal -SSV sequence that is a putative recognition site of syntrophins - molecules that are integral parts of the dystrophin complex [27, 45-47]. It is now well established that this complex is responsible for the anchoring of AQP4 in brain astrocytes and that $\alpha 1$-syn is the immediate anchor for a major fraction of endfoot AQP4 in these cells [27-29, 46].
In the case of Müller cells, it remains to identify the anchoring molecules that dictate their functional polarization. Targeted deletion of $\alpha 1$-syn had only a modest effect on AQP4 expression in a mixed sample of retinal astrocytic and Müller cell processes [48] and no significant effect on AQP4 expression in perivascular Müller cell processes specifically sampled from the outer plexiform layer of the retina [30].

Here we provide evidence of an alternative anchoring mechanism for AQP4 that distinguishes Müller cells from brain macroglia. Specifically, we show that targeted deletion of $\beta 1$-syn causes a partial loss of AQP4 from Müller cell endfeet and an almost complete loss if combined with a deletion of $\alpha 1$-syn. Double knockout mice retained less than $10 \%$ of their AQP4 pool in Müller cell endfeet. One would expect a residual AQP4 pool of this 

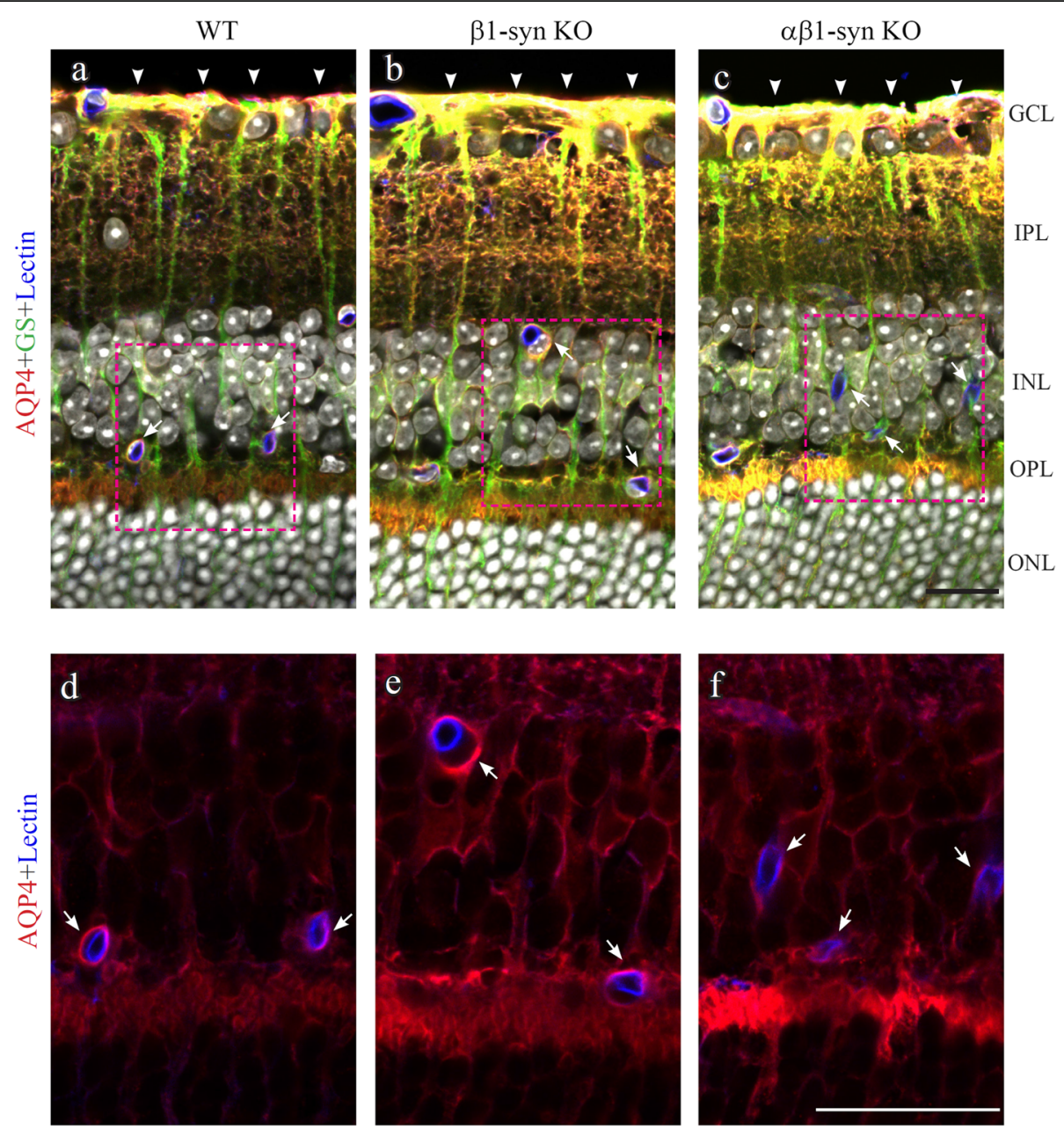

Fig. 2 Immunofluorescence localization of AQP4 in retina. Confocal image showing AQP4 (in red), the Müller cell marker glutamine synthetase (GS; in green) and the endothelial marker lectin (in blue). AQP4 is concentrated in the perivascular (arrows) and in subvitreal membrane domains (arrowheads) in the WT (a and $\mathbf{d}$ ) and $\beta 1$-syn KO (b and $\mathbf{e}$ ) animals. Perivascular AQP4 staining is strongly reduced in aß1-syn KO mice (c and $\mathbf{f}$ ). In both the knockouts, AQP4 labeling is increased along the entire length of Müller cell and around the inner nuclear layer. Nuclear staining is shown in white. GCL-ganglion cell layer; IPL-inner plexiform layer; INL-inner nuclear layer; OPL-outer plexiform layer; ONL-outer nuclear layer. Scale bars $=20 \mu \mathrm{m}$

size even after a complete interruption of the specific anchoring mechanisms in endfoot membranes. Thus, AQP4 is found in the Müller cell membrane at large, at a density corresponding to $10 \%$ of that in perivascular membrane domains [39].

These findings, together with the unchanged levels of $\mathrm{AQP} 4$ protein and transcript levels in $\beta 1$-syn $\mathrm{KO}$ mice retinae, confirm that the loss of AQP4 from the perivascular membranes is due to a mislocalization of AQP4 rather than an overall change in transcription or translation.

Mice with single knockout of $\alpha 1$-syn showed no significant reduction in AQP4 from Müller cell endfeet, thus confirming previous studies based on selective sampling of Müller cell processes. How then could deletion of $\alpha 1$-syn have such a strong additive effect when combined with the deletion of $\beta 1$-syn? Judged by the faint immunohistochemical signal, $\alpha 1-$ syn is weakly expressed in Müller cell endfoot membranes, thus explaining why single $\alpha 1$-syn $\mathrm{KO}$ mice retain their endfoot pool of AQP4. A key finding in the present study is that of a marked upregulation of $\alpha 1$-syn following $\beta 1$-syn deletion. The most salient explanation of our findings is that this increase in $\alpha 1$-syn partially substitutes for the loss of $\beta 1$-syn. Thus, only if both syntrophins are missing will the endfoot pool of AQP4 be removed.

The present study indicates that $\alpha 1$-syn partially compensates for a deletion of $\beta 1$-syn but that $\beta 1$-syn expression is resistant to $\alpha 1$-syn $\mathrm{KO}$. The question remains whether there are additional syntrophins that should be considered in the context of Müller cell function. The retina shows an abundance of $\gamma 2$-syntrophin ( $\gamma 2$-syn), as judged by our quantitative PCR data [32]. While $\gamma 2$-syn knockout mice are not available as yet, the dramatic 

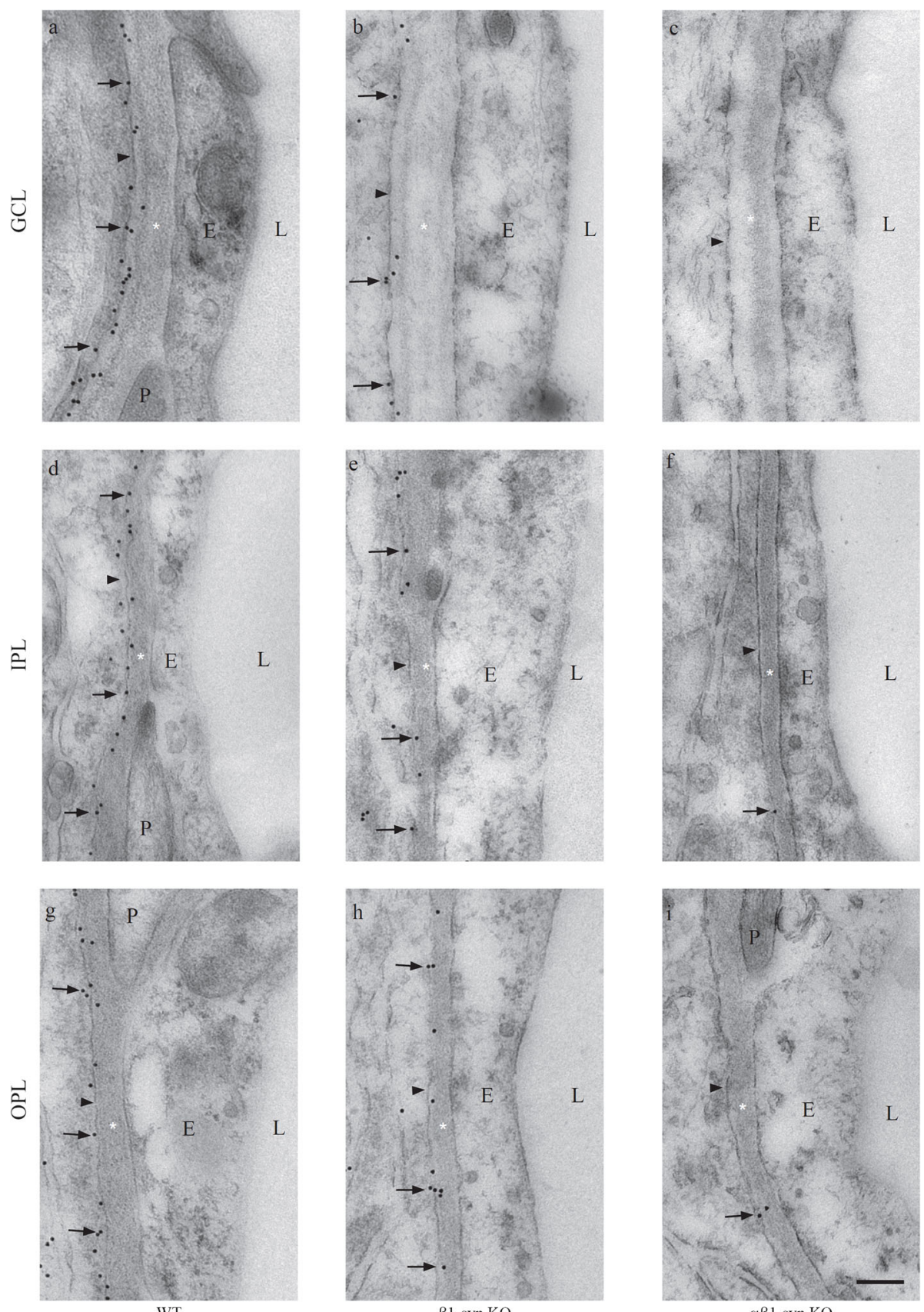

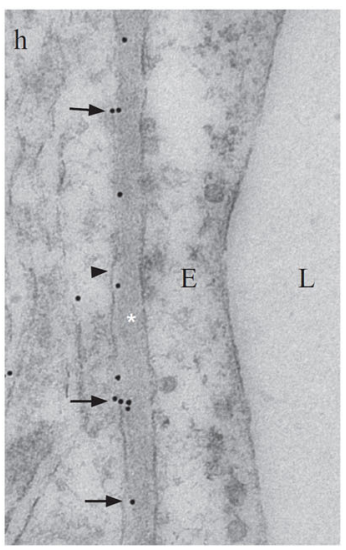

$\beta 1$-syn KO

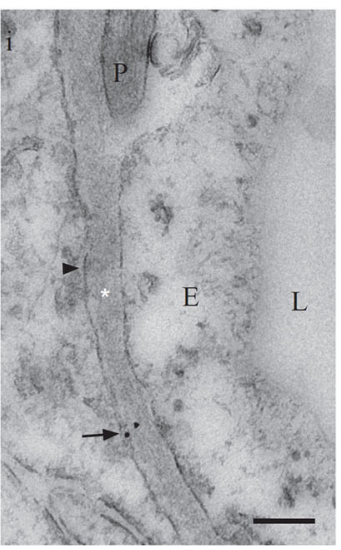

$\alpha \beta 1$-syn KO

Fig. 3 Electron micrographs showing AQP4 immunogold labeling in different vascular layers of the retina. The perivascular Müller cell membrane shows high density of immunogold labeling for AQP4 in WT retina $(\mathbf{a}, \mathbf{d}$, and $\mathbf{g})$. Significant reduction in perivascular AQP4 labeling is seen in mice lacking $\beta 1$-syn ( $\mathbf{b}$, e and $\mathbf{h}$ ). A near complete loss of perivascular AQP4 labeling is seen in mice that lack both a1-and $\beta 1$-syn (c, $\mathbf{f}$ and $\mathbf{i}$ ). The arrowheads point to the endfoot domain facing the blood vessel. GCL-ganglion cell layer; IPL-inner plexiform layer; OPL-outer plexiform layer; L-lumen; E-endothelium; P-pericyte; * $=$ basement membrane. Scale bar $=200 \mathrm{~nm}$

effect of the $\alpha \beta 1$-syn double knockout on AQP4 polarization leaves little room for a contribution by $\gamma 2$ syn. This is consistent with data suggesting that $\gamma 2$-syn is expressed in neurons rather than in glia $[48,49]$. As to $\beta 2$-syn, this syntrophin has a distribution that is not consistent with a role in AQP4 anchoring and is predominantly found in the OPL [48]. Taken together, our data suggest that AQP4 anchoring in astrocytic endfoot membranes of retinal Müller cells mainly depends on expression of $\beta 1$-syn and that $\alpha 1$-syn either partially (in perivascular membranes) or completely (in subvitreal membranes) compensates for $\beta 1$-syn when the latter is 
a
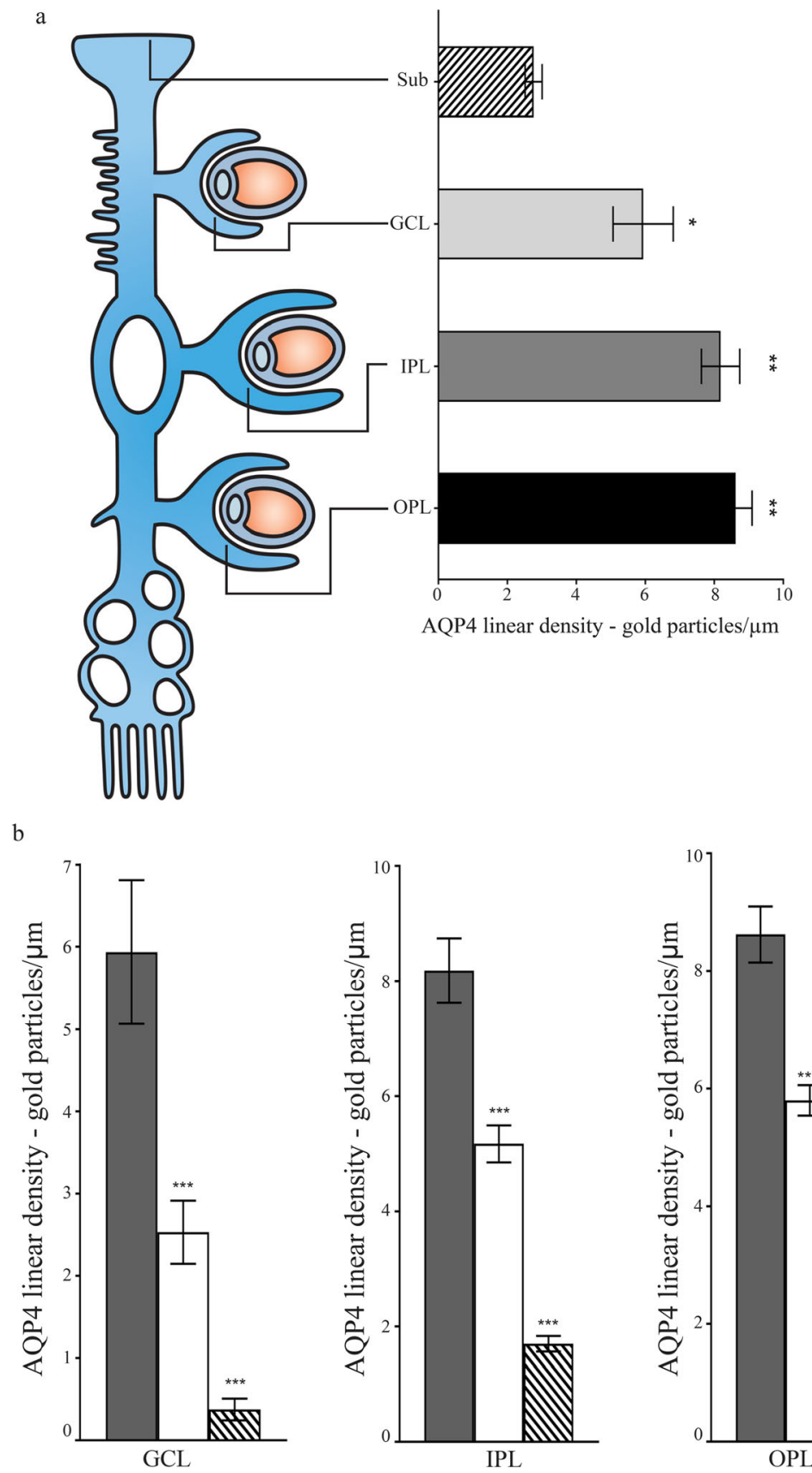

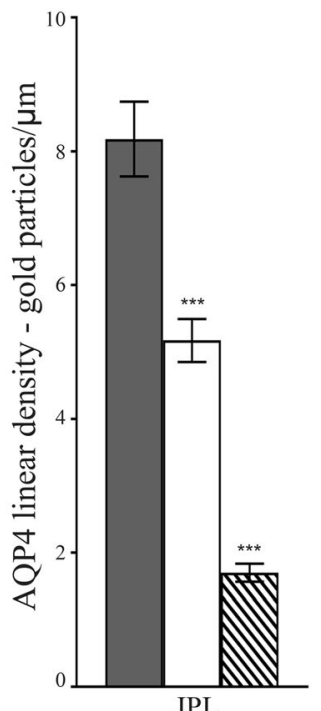

IPL
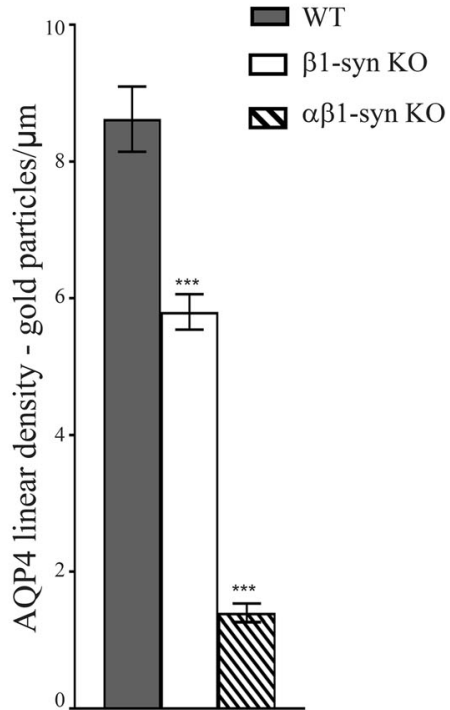

OPL

Fig. 4 Quantitative analysis of the AQP4 immunogold labeling in different subregions of retina. a Schematic figure comparing the AQP4 distribution at the perivascular endfeet of the WT Müller cells in different layers i.e. outer plexiform layer (OPL), inner plexiform layer (IPL), ganglion cell layer (GCL) and the subvitreal endfeet (Sub). The AQP4 immunogold labeling ( $n=4$ mice) in Sub was significantly lower than GCL, IPL and OPL. b Quantitative analysis of AQP4 immunogold labeling in different retinal layers of WT, $\beta 1$-syn KO and a 1 1-syn KO mice. In mice lacking $\beta 1$-syn, there was a significant reduction in the mean linear density of gold particles when compared with WT controls in all layers. In the double knockout mice, there was a near complete loss of perivascular labeling of AQP4 when compared with WT controls in all the layers ( $n=4$ for each genotype). Statistics: one-way ANOVA and post hoc Scheffé test. Data shown as mean \pm SEM. ${ }^{*} p<.05 ;{ }^{* *} p<.01 ;{ }^{* * *} p<.001$

knocked out. A compensatory upregulation of $\alpha 1$-syn was also observed in the skeletal muscle of $\beta 1$-syn-KO mice [31].

In the present study we have used the well documented endfoot accumulation of AQP4 as a proxy for macroglial polarization. Our results suggest that the functional specialization of Müller cell membranes depends on an interplay between two syntrophin isoforms. While the effect of $\beta 1$-syn knockout is partly compensated for by an upregulation of $\alpha 1$-syn, there is no 

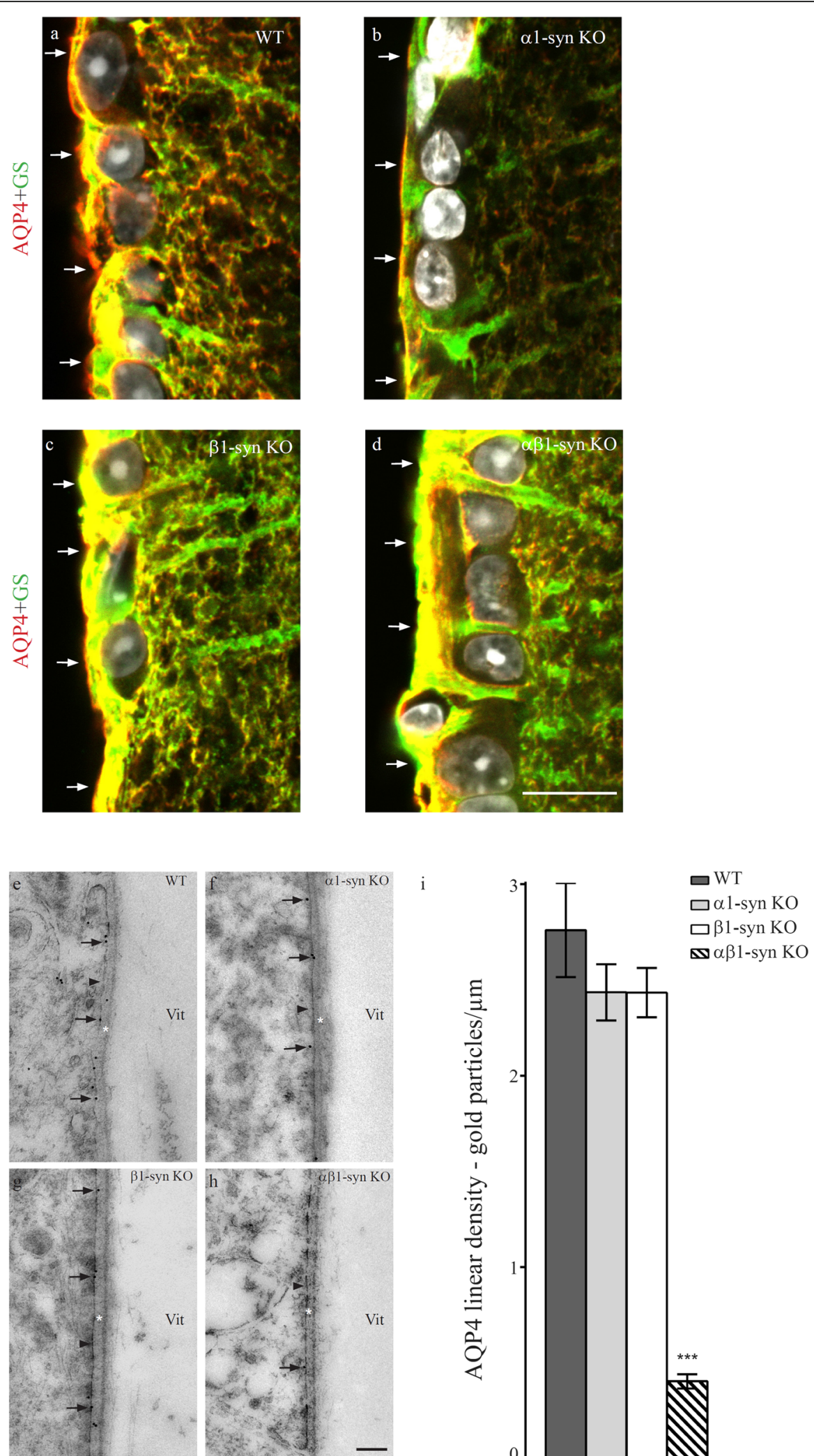

it

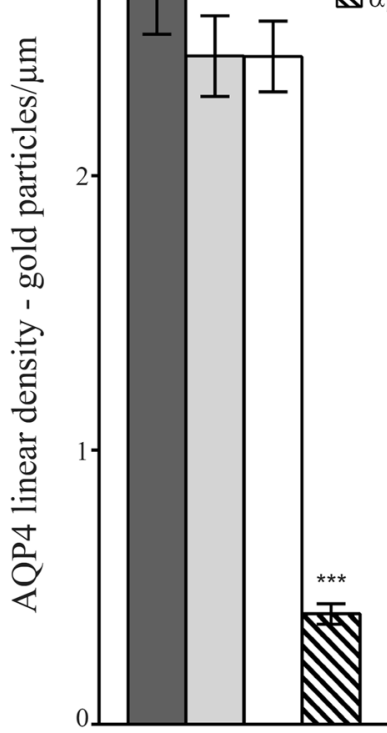

Fig. 5 (See legend on next page.) 
(See figure on previous page.)

Fig. 5 AQP4 localization requires the presence of both a1- and B1-syn in subvitreal domain. AQP4 (in red) is highly concentrated in the subvitreal membrane domains (arrows in $\mathbf{a}$ ) in the WT animals. Deletion of either a1-syn (arrows in $\mathbf{b}$ ) or $\beta 1$-syn (arrows in $\mathbf{c}$ ) alone does not affect AQP4 localization. Concomitant deletion of both a1- and $\beta 1$-syn results in near complete loss of AQP4 (arrows in $\mathbf{d}$ ). Nuclear staining is shown in white and Müller cell marker, glutamine synthetase (GS), is shown in green. Scale bar $=20 \mu \mathrm{m}$. Representative high resolution immunogold electron micrographs showing AQP4 localization in subvitreal domain. Concomitant deletion of both a1- and B1-syn results in near complete loss of AQP4 in subvitreal domain (e to $\mathbf{h}$ ). Quantitative immunogold analysis shows a near complete loss of AQP4 in subvitreal domain (i; $n=4$ for each group). Statistics: one-way ANOVA and post hoc Scheffé test. The arrowheads point to the endfoot domain facing the vitreous. Vit-vitreous body; ${ }^{*}=$ basement membrane. Data shown as mean \pm SEM. Scale bar $=200 \mathrm{~nm} .{ }^{* * *} \mathrm{p}<.001$

a WT1 KO1 WT2 KO2 WT3 KO3 WT4 KO4 WT5 KO5 $60 \mathrm{kDa}$ $\sim 40 \mathrm{kDa}$

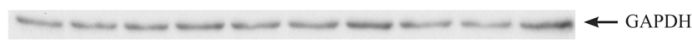

b

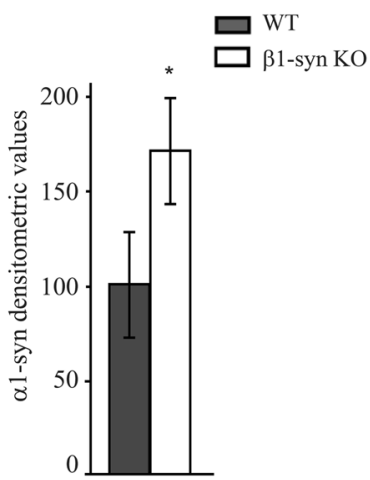

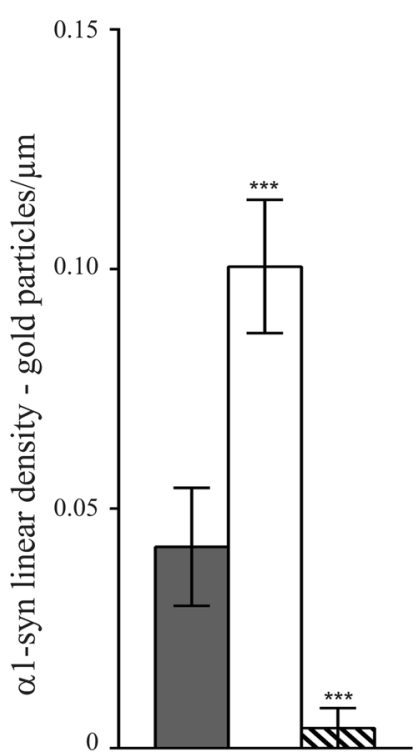

d

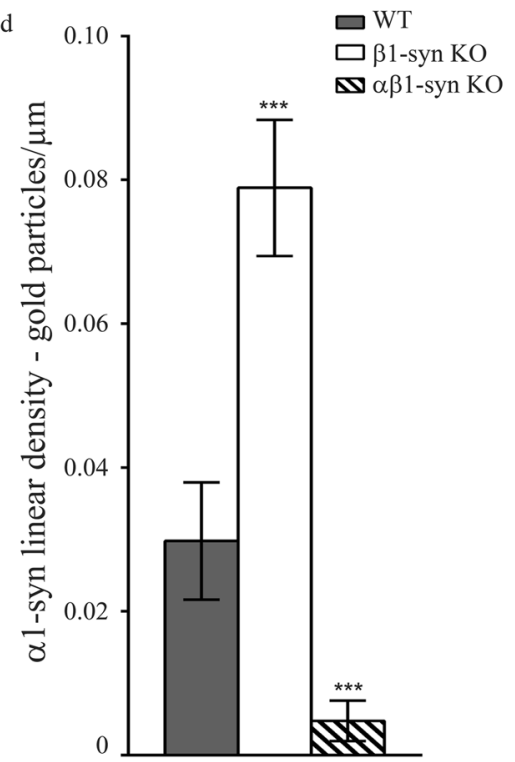

Fig. 6 a1-syn protein level is increased in retinae of $\beta 1$-syn $\mathrm{KO}$ mice. a Immunoblot showing a1-syn expression in total retinal protein lysates from $W T$ and $\beta 1$-syn $\mathrm{KO}$ retinae. Statistical analysis of a1-syn expression in WT and $\beta 1$-syn $\mathrm{KO}$ shows that a1-syn protein level is significantly increased in $\beta 1$-syn KO retina compared to WT ( $\mathbf{b} ; n=5$ for each group). Statistics: independent samples t-test. Densitometric values are expressed as percentage of average WT values \pm SD. ${ }^{*} p<.05$. GAPDH was used as the loading control. Quantitative immunogold analysis showing a1-syn is increased in $\beta 1$-syn $K O$ retina, both in perivascular domain ( $\mathbf{c} ; n=4$ for each group) and in subvitreal domain $(\mathbf{d} ; n=4$ for each group). Statistics: one-way ANOVA and post hoc Scheffé test. Data shown as mean \pm SEM. ${ }^{* * *} p<.001$ 


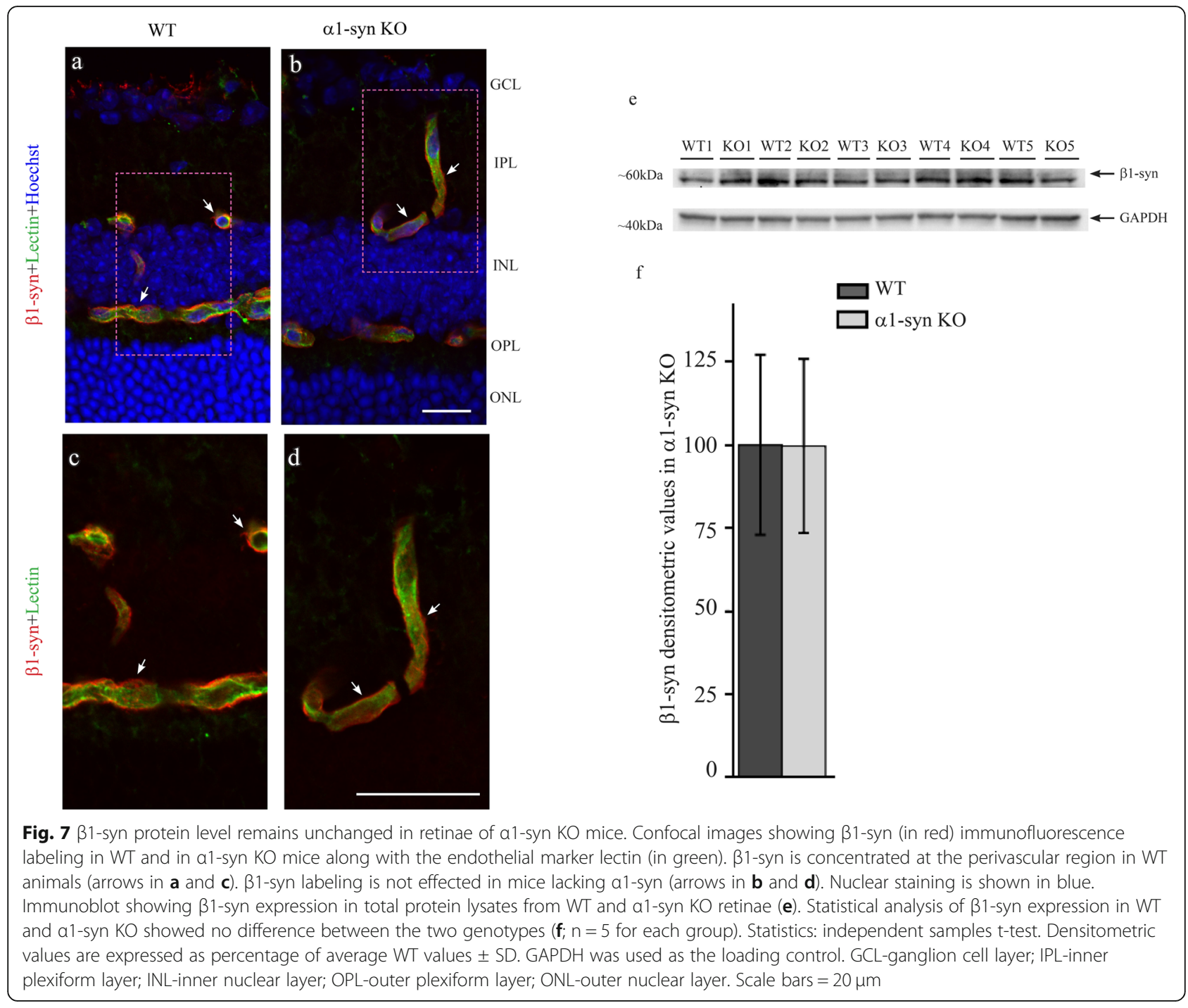

change in $\beta 1$-syn expression following targeted deletion of the gene encoding $\alpha 1$-syn. Previously, we showed that $\beta 1$-syn is also responsible for the anchoring of a substantial fraction of the $\mathrm{K}_{\mathrm{ir}} 4.1$ pool in Müller cell endfeet [32]. There was no additive effect on $\mathrm{K}_{\mathrm{ir}} 4.1$ depletion in animals that lacked $\alpha 1$-syn as well as $\beta 1$-syn. Taken together these studies suggest that $\beta 1$-syn binds to $K_{\text {ir }} 4.1$ as well as AQP4 and that $\alpha 1$-syn couples less efficiently to the $\mathrm{C}$-terminal end of $\mathrm{K}_{\mathrm{ir}} 4.1$ than to the $\mathrm{C}$-terminal end of AQP4.

\section{Supplementary information}

Supplementary information accompanies this paper at https://doi.org/10. 1186/s13041-020-00581-w.

Additional file 1 Figure $\mathbf{S} \mathbf{1} \mathrm{qPCR}$ analysis of total RNA extracted from retinae using primers specific for Aqp4. No statistically significant difference in total Aqp4 gene expression was observed between the WT, a1-syn $\mathrm{KO}$ and aß1-syn $\mathrm{KO}$ mice ( $n=4$ for each group). Statistics: MannWhitney U-test. Top was used as the normalization gene. Data shown as mean \pm SEM. Figure S2 Control experiment for AQP4 antibody specificity. AQP4 antibody specificity was confirmed by incubating the retina samples from AQP4 KO and WT mice with the antibody. Confocal image showing a lack of specific labeling confirming the specificity of the antibody (panels a and b). GCL-ganglion cell layer; IPL-inner plexiform layer; INL-inner nuclear layer; OPL-outer plexiform layer; ONL-outer nuclear layer. Scale bars $=20 \mu \mathrm{m}$. Bottom: Immunogold staining also revealed a lack gold particles signaling AQP4 (bottom panel). Scale bar $=200 \mathrm{~nm}$. Figure $\mathbf{S 3}$ Electron micrographs from an AQP4 KO mouse retina section subjected to immunogold procedure using the anti-AQP4 antibody. There is no AQP4 immunogold labeling at the perivascular Müller cell endfeet in the three retinal vascular layers (a-c). GCL-ganglion cell layer; IPL-inner plexiform layer; OPL-outer plexiform layer; L-lumen; Eendothelium; P-pericyte; * = basement membrane. The arrowheads point to the endfoot domain facing the blood vessel. Scale bar $=1 \mu \mathrm{m}$. Figure S4 Perivascular AQP4 localization is retained in retina of a1-syn KO mice. Confocal images showing AQP4 (in red) immunofluorescence labeling in WT and in a1-syn KO mice along with the endothelial marker lectin (in green). AQP4 is concentrated at the perivascular region in WT animals (arrows in panels a and c). AQP4 labeling is retained in mice lacking a1-syn (arrows in panels $b$ and $d$ ). Nuclear staining is shown in blue. GCLganglion cell layer; IPL-inner plexiform layer; INL-inner nuclear layer; OPLouter plexiform layer; ONL-outer nuclear layer. Scale bars $=20 \mu \mathrm{m}$. Immunoblot showing AQP4 expression in total protein lysates from WT and 
a1-syn $\mathrm{KO}$ retinae (panel e). Statistical analysis of AQP4 expression in WT and a1-syn KO showed no difference between the two genotypes (pane $f_{;} n=5$ for each group). Statistics: independent samples t-test. Densitometric values are expressed as percentage of average WT values \pm SD. GAPDH was used as the loading control. High resolution electron micrographs showing perivascular labeling of AQP4 in WT and a1-syn KO mice (panels $\mathrm{g}$ and $\mathrm{h}$ ). Quantitative immunogold analysis revealed no statistical difference between the two genotypes, in any of the layers (panel i; $n=4$ for each group). Statistics: one-way ANOVA and post hoc Scheffé test. GCL-ganglion cell layer; IPL-inner plexiform layer; OPL-outer plexiform layer; L-lumen; E-endothelium; ${ }^{*}=$ basement membrane. The arrowheads point to the endfoot domain facing the blood vessel. Data shown as mean \pm SEM. Scale bar $=200 \mathrm{~nm}$. Figure S5 AQP4 localization in subvitreal domain of retinal Müller cells. AQP4 shown in red is highly concentrated in the subvitreal membrane domains (arrows in $a$ and b) in the WT animals. Subvitreal localization of AQP4 is retained in mice that lack either a1-syn (arrows in $\mathrm{c}$ and d) or $\beta 1$-syn (arrows in e and f). Deletion of both a1- and $\beta 1$-syn results in near complete loss of AQP4 at the subvitreal Müller cell domains (arrows in $\mathrm{g}$ and $\mathrm{h}$ ). Note a more distinct membrane staining of Müller cell stem processes in the aß1-syn KO (arrowheads in $\mathrm{g}$ and h) compared to the other genotypes (arrowheads in a-f). Nuclei, mainly belonging to ganglion neurons, are visualized by nuclear labeling (grey and white in figures $a, c$, e and g). Glutamine synthetase (GS) is used as the marker of Müller cell cytosol and is shown in green. Scale bar $=20 \mu \mathrm{m}$. Figure S6 Electron micrographs showing a1-syn labeling in perivascular Müller cell domains. Immunogold labeling of a1-syn is seen in retinae of WT (arrow in a) and B1-syn KO (arrows in c) mice. The immunogold particles are indicated by arrows. The labeling is very sparse but quantitative analysis of the immunogold labeling (main figure Fig. $6 \mathrm{c}$ and d) shows a significant difference between WT and $\beta 1$-syn $\mathrm{KO}$ mice. Lack of immunogold particles is seen in a1-syn $\mathrm{KO}(\mathrm{b})$, and aß1-syn $\mathrm{KO}$ (d) mice. The arrowheads point to the endfoot domain facing the blood vessel. L-lumen; E-endothelium; ${ }^{*}=$ basement membrane. Scale bar $=200$ $\mathrm{nm}$. Figure S7 Increased labeling of a1-syn in $\beta 1$-syn KO retina. Confocal immunofluorescent images showing a1-syn (in red) labeling in retinae of WT (top panels) and $\beta 1$-syn KO (bottom panels) mice. In mice lacking $\beta 1-$ syn, there was an increased labeling of a1-syn when compared to WT. Endothelial marker lectin is shown in green. Nuclear staining is shown in blue. Scale bars $=20 \mu \mathrm{m}$

Additional file 2.

\section{Abbreviations}

AQP4: Aquaporin-4; BSA: Bovine serum albumin; DAP: Dystrophin associated protein; GCL: Ganglion cell layer; IPL: Inner plexiform layer; INL: Inner nuclear layer; OPL: Outer plexiform layer; ONL: Outer nuclear layer; Sub: Subvitreal; PB: Phosphate buffer; PBS: Phosphate buffered saline; HSA: Human serum albumin; GAPDH: Glyceraldehyde 3-phosphate dehydrogenase; TBP: TATAbox binding protein; RT: Room temperature; TBS: Tris buffered saline; WT: Wild type; KO: Knock-out; a1-syn: a1-syntrophin; $\beta 1$-syn: $\beta 1$-syntrophin; RRID: Research resource identifier (see scicrunch.org)

\section{Acknowledgements}

We are grateful to Bjørg Riber, Karen-Marie Gujord, Grazyna Babinska and Bashir Hakim for technical assistance, Prof. Emeritus Finn-Mogens Haug and Dr. Paul Johannes Helm for assistance with the analySIS program and to Gunnar F. Lothe and Carina Knudsen for the artwork.

\section{Authors' contributions}

Conceptualization, Amiry-Moghaddam M, Katoozi S, Rao SB; Experimental work and analyses, Rao SB, Katoozi S, Skauli N; Resources, Adams ME, Froehner SC, AmiryMoghaddam M, Writing - Original Draft Preparation, Katoozi S, Rao SB, AmiryMoghaddam M, Ottersen OP; Writing - Review \& Editing, Rao SB, Katoozi S, Skauli N, Froehner SC, Adams ME, Amiry-Moghaddam M, Ottersen OP; Supervision, Amiry Moghaddam M; The authors read and approved the final manuscript.

\section{Funding}

The authors wish to thank the funding provided by the European Union (EU) through project FP7-PEOPLE-2012-ITN 316832-OLIMPIA, and National Institutes of Health (NIH), USA, NS14871.

\section{Availability of data and materials}

All the datasets used and analyzed during this study are available from the corresponding author upon reasonable request.

\section{Ethics approval}

All the experimental procedures performed on mice were approved by the Institutional Animal Care and Use Committee of the University of Washington (\#3298-02) and according to the European Council law on protection of laboratory animals, with the approval of the University of Oslo's Animal Care and Use Committee (FOTS ID 8572). Every effort was made to minimize the number of animals.

\section{Consent for publication}

All authors consent to the publication.

\section{Competing interests}

The authors declare that they have no competing interests.

\section{Author details}

'Division of Anatomy, Department of Molecular Medicine, Institute of Basic Medical Sciences, University of Oslo, Post box 1105, Blindern, 0317 Oslo, Norway. ${ }^{2}$ Department of Physiology and Biophysics, University of Washington, Seattle, WA 98195-7290, USA. ${ }^{3}$ Present Address: President's office, Karolinska Institutet, Nobels väg 6, 17177 Stockholm, Sweden.

\section{Received: 17 January 2020 Accepted: 6 March 2020}

Published online: 16 March 2020

\section{References}

1. Amiry-Moghaddam M, Ottersen OP. The molecular basis of water transport in the brain. Nat Rev Neurosci. 2003;4:991-1001.

2. Benfenati $V$, Ferroni S. Water transport between CNS compartments: functional and molecular interactions between aquaporins and ion channels. Neuroscience. 2010;168:926-40.

3. Reichenbach A, Bringmann A. New functions of Muller cells. Glia. 2013;61:651-78.

4. Verkhratsky A, Nedergaard M. Physiology of Astroglia. Physiol Rev. 2018;98:239-389.

5. Brew H, Gray PTA, Mobbs P, Attwell D. Endfeet of retinal glial-cells have higher densities of ion channels that mediate K+ buffering. Nature. 1986; 324:466-8.

6. Newman EA. Regional specialization of retinal glial cell membrane. Nature. 1984;309:155-7.

7. Newman EA. Membrane physiology of retinal glial (Muller) cells. J Neurosci. 1985:5:2225-39.

8. Newman EA. Distribution of potassium conductance in mammalian Muller (glial) cells: a comparative study. J Neurosci. 1987;7:2423-32.

9. Newman EA. Inward-rectifying potassium channels in retinal glial (Muller) cells. J Neurosci. 1993:13:3333-45.

10. Pannicke T, Uckermann O, landiev I, Wiedemann P, Reichenbach A, Bringmann A. Ocular inflammation alters swelling and membrane characteristics of rat Muller glial cells. J Neuroimmunol. 2005;161:145-54.

11. Pannicke T, Ivo Chao T, Reisenhofer M, Francke M, Reichenbach A. Comparative electrophysiology of retinal Muller glial cells-a survey on vertebrate species. Glia. 2017;65:533-68.

12. Connors NC, Kofuji P. Dystrophin Dp71 is critical for the clustered localization of potassium channels in retinal glial cells. J Neurosci. 2002;22:4321-7.

13. Kofuji $P$, Connors NC. Molecular substrates of potassium spatial buffering in glial cells. Mol Neurobiol. 2003;28:195-208.

14. Kofuji P, Newman EA. Potassium buffering in the central nervous system. Neuroscience. 2004;129:1045-56.

15. Butt AM, Kalsi A. Inwardly rectifying potassium channels (Kir) in central nervous system glia: a special role for Kir4.1 in glial functions. J Cell Mol Med. 2006;10:33-44.

16. Nagelhus EA, Horio Y, Inanobe A, Fujita A, Haug FM, Nielsen S, Kurachi Y, Ottersen OP. Immunogold evidence suggests that coupling of $K_{+}$ siphoning and water transport in rat retinal Muller cells is mediated by a coenrichment of Kir4.1 and AQP4 in specific membrane domains. Glia. 1999; 26:47-54.

17. Ishii M, Horio $Y$, Tada $Y$, Hibino H, Inanobe A, Ito M, Yamada M, Gotow T, Uchiyama $Y$, Kurachi $Y$. Expression and clustered distribution of an inwardly rectifying potassium channel, KAB-2/Kir4.1, on mammalian retinal Muller cell 
membrane: their regulation by insulin and laminin signals. J Neurosci. 1997; 17:7725-35.

18. Kofuji P, Ceelen P, Zahs KR, Surbeck LW, Lester HA, Newman EA. Genetic inactivation of an inwardly rectifying potassium channel (Kir4.1 subunit) in mice: phenotypic impact in retina. J Neurosci. 2000;20:5733-40.

19. Nagelhus EA, Ottersen OP. Physiological roles of aquaporin-4 in brain. Physiol Rev. 2013;93:1543-62.

20. Papadopoulos MC, Verkman AS. Aquaporin water channels in the nervous system. Nat Rev Neurosci. 2013;14:265-77.

21. Eid T, Lee TSW, Thomas MJ, Amiry-Moghaddam M, Bjornsen LP, Spencer $\mathrm{DD}$, Agre $\mathrm{P}$, Ottersen OP, de Lanerolle NC. Loss of perivascular aquaporin 4 may underlie deficient water and $\mathrm{K}+$ homeostasis in the human epileptogenic hippocampus. Proc Natl Acad Sci U S A. 2005;102:1193-8.

22. landiev I, Pannicke T, Biedermann B, Wiedemann P, Reichenbach A, Bringmann A. Ischemia-reperfusion alters the immunolocalization of glial aquaporins in rat retina. Neurosci Lett. 2006;408:108-12.

23. Yang J, Lunde LK, Nuntagij P, Oguchi T, Camassa LM, Nilsson LN, Lannfelt L, Xu Y, Amiry-Moghaddam M, Ottersen OP, Torp R. Loss of astrocyte polarization in the tg-ArcSwe mouse model of Alzheimer's disease. Alzheimers Dis. 2011;27:711-22.

24. Alvestad S, Hammer J, Hoddevik EH, Skare O, Sonnewald U, AmiryMoghaddam M, Ottersen OP. Mislocalization of AQP4 precedes chronic seizures in the kainate model of temporal lobe epilepsy. Epilepsy Res. 2013; 105:30-41.

25. Pannicke T, Wurm A, landiev I, Hollborn M, Linnertz R, Binder DK, Kohen L, Wiedemann P, Steinhauser C, Reichenbach A, Bringmann A. Deletion of aquaporin-4 renders retinal glial cells more susceptible to osmotic stress. J Neurosci Res. 2010;88:2877-88.

26. Smith AJ, Duan T, Verkman AS. Aquaporin-4 reduces neuropathology in a mouse model of Alzheimer's disease by remodeling peri-plaque astrocyte structure. Acta Neuropathol Commun. 2019;7:74.

27. Neely JD, Amiry-Moghaddam M, Ottersen OP, Froehner SC, Agre P, Adams ME. Syntrophin-dependent expression and localization of Aquaporin-4 water channel protein. Proc Natl Acad Sci U S A. 2001;98:14108-13.

28. Amiry-Moghaddam M, Otsuka T, Hurn PD, Traystman RJ, Haug FM, Froehner SC, Adams ME, Neely JD, Agre P, Ottersen OPT, Bhardwaj A. An alphasyntrophin-dependent pool of AQP4 in astroglial end-feet confers bidirectional water flow between blood and brain. Proc Natl Acad Sci U S A. 2003;100:2106-11.

29. Hoddevik EH, Khan FH, Rahmani S, Ottersen OP, Boldt HB, AmiryMoghaddam M. Factors determining the density of AQP4 water channel molecules at the brain-blood interface. Brain Struct Funct. 2017;222:1753-66.

30. Enger R, Gundersen GA, Haj-Yasein NN, Eilert-Olsen M, Thoren AE, Vindedal GF, Petersen PH, Skare O, Nedergaard M, Ottersen OP, Nagelhus EA. Molecular scaffolds underpinning macroglial polarization: an analysis of retinal Muller cells and brain astrocytes in mouse. Glia. 2012;60:2018-26.

31. Kim MJ, Whitehead NP, Bible KL, Adams ME, Froehner SC. Mice lacking alpha-, beta1- and beta2-syntrophins exhibit diminished function and reduced dystrophin expression in both cardiac and skeletal muscle. Hum Mol Genet. 2019;28:386-95.

32. Rao SB, Katoozi S, Skauli N, Froehner SC, Ottersen OP, Adams ME, AmiryMoghaddam M. Targeted deletion of beta1-syntrophin causes a loss of Kir 4.1 from Muller cell endfeet in mouse retina. Glia. 2019;67:1138-49.

33. Adams ME, Kramarcy N, Krall SP, Rossi SG, Rotundo RL, Sealock R, Froehner SC. Absence of a-Syntrophin leads to structurally aberrant neuromuscular synapses deficient in Utrophin. J Cell Biol. 2000;150:1385-98.

34. Thrane AS, Rappold PM, Fujita T, Torres A, Bekar LK, Takano T, Peng W, Wang F, Rangroo Thrane V, Enger R, et al. Critical role of aquaporin-4 (AQP4) in astrocytic $\mathrm{Ca} 2+$ signaling events elicited by cerebral edema. Proc Natl Acad Sci U S A. 2011;108:846-51.

35. Mathiisen TM, Lehre KP, Danbolt NC, Ottersen OP. The perivascular astroglial sheath provides a complete covering of the brain microvessels: an electron microscopic 3D reconstruction. Glia. 2010;58:1094-103.

36. Prydz A, Stahl K, Puchades M, Davarpaneh N, Nadeem M, Ottersen OP, Gundersen V, Amiry-Moghaddam M. Subcellular expression of aquaporin-4 in substantia nigra of normal and MPTP-treated mice. Neuroscience. 2017;359:258-66.

37. Katoozi S, Skauli N, Rahmani S, Camassa LMA, Boldt HB, Ottersen OP, AmiryMoghaddam M. Targeted deletion of Aqp4 promotes the formation of astrocytic gap junctions. Brain Struct Funct. 2017;222:3959-72.

38. Peters MF, Adams ME, Froehner SC. Differential association of syntrophin pairs with the dystrophin complex. J Cell Biol. 1997;138:81-93.
39. Nagelhus EA, Veruki ML, Torp R, Haug F-M, Laake JH, Nielsen S, Agre P, Ottersen OP. Aquaporin-4 Water Channel protein in the rat retina and optic nerve: polarized expression in Müller cells and fibrous astrocytes. J Neurosci. 1998:18:2506-19.

40. Amiry-Moghaddam M, Ottersen OP. Immunogold cytochemistry in neuroscience. Nat Neurosci. 2013;16:798-804.

41. Lunde LK, Camassa LM, Hoddevik EH, Khan FH, Ottersen OP, Boldt HB, Amiry-Moghaddam M. Postnatal development of the molecular complex underlying astrocyte polarization. Brain Struct Funct. 2015;220:2087-101.

42. Frydenlund DS, Bhardwaj A, Otsuka T, Mylonakou MN, Yasumura T, Davidson KG, Zeynalov E, Skare O, Laake P, Haug FM, et al. Temporary loss of perivascular aquaporin-4 in neocortex after transient middle cerebral artery occlusion in mice. Proc Natl Acad Sci U S A. 2006;103:13532-6.

43. Dalloz C, Sarig R, Fort P, Yaffe D, Bordais A, Pannicke T, Grosche J, Mornet D, Reichenbach A, Sahel J, et al. Targeted inactivation of dystrophin gene product Dp71: phenotypic impact in mouse retina. Hum Mol Genet. 2003; 12:1543-54.

44. Fort PE, Sene A, Pannicke T, Roux MJ, Forster V, Mornet D, Nudel U, Yaffe D, Reichenbach A, Sahel JA, Rendon A. Kir4.1 and AQP4 associate with Dp71and utrophin-DAPs complexes in specific and defined microdomains of Muller retinal glial cell membrane. Glia. 2008;56:597-610.

45. Constantin B. Dystrophin complex functions as a scaffold for signalling proteins. Biochim Biophys Acta. 1838;2014:635-42.

46. Amiry-Moghaddam M, Frydenlund DS, Ottersen OP. Anchoring of aquaporin-4 in brain: molecular mechanisms and implications for the physiology and pathophysiology of water transport. Neuroscience. 2004;129: 999-1010

47. Blake DJ, Weir A, Newey SE, Davies KE. Function and genetics of dystrophin and dystrophin-related proteins in muscle. Physiol Rev. 2002;82:291-329.

48. Puwarawuttipanit W, Bragg AD, Frydenlund DS, Mylonakou MN, Nagelhus EA, Peters MF, Kotchabhakdi N, Adams ME, Froehner SC, Haug FM, et al. Differential effect of alpha-syntrophin knockout on aquaporin-4 and Kir4.1 expression in retinal macroglial cells in mice. Neuroscience. 2006;137:165-75.

49. Piluso G, Mirabella M, Ricci E, Belsito A, Abbondanza C, Servidei S, Puca AA, Tonali P, Puca GA, Nigro V. Gamma1- and gamma2-syntrophins, two novel dystrophin-binding proteins localized in neuronal cells. J Biol Chem. 2000; 275:15851-60.

\section{Publisher's Note}

Springer Nature remains neutral with regard to jurisdictional claims in published maps and institutional affiliations.

Ready to submit your research? Choose BMC and benefit from:

- fast, convenient online submission

- thorough peer review by experienced researchers in your field

- rapid publication on acceptance

- support for research data, including large and complex data types

- gold Open Access which fosters wider collaboration and increased citations

- maximum visibility for your research: over $100 \mathrm{M}$ website views per year

At $\mathrm{BMC}$, research is always in progress.

Learn more biomedcentral.com/submission 